Research Article

\title{
Improved Adhesion of Nonfluorinated ZnO Nanotriangle Superhydrophobic Layer on Glass Surface by Spray-Coating Method
}

\author{
Norfatehah Basiron, ${ }^{1}$ Srimala Sreekantan ${ }^{(D},{ }^{1}$ Khairul Arifah Saharudin, ${ }^{1}$ \\ Zainal Arifin Ahmad, ${ }^{1}$ and Vignesh Kumaravel $\mathbb{1}^{2}$ \\ ${ }^{1}$ School of Materials and Mineral Resources Engineering, Engineering Campus, Universiti Sains Malaysia, 14300 Nibong Tebal, \\ Pulau Pinang, Malaysia \\ ${ }^{2}$ Department of Environmental Science, School of Science, Institute of Technology Sligo, Ash Lane, Sligo, Ireland
}

Correspondence should be addressed to Srimala Sreekantan; srimala@usm.my and Vignesh Kumaravel; vignesh134@gmail.com

Received 25 June 2018; Accepted 3 September 2018; Published 21 October 2018

Academic Editor: Oscar Perales-Pérez

Copyright (c) 2018 Norfatehah Basiron et al. This is an open access article distributed under the Creative Commons Attribution License, which permits unrestricted use, distribution, and reproduction in any medium, provided the original work is properly cited.

\begin{abstract}
In this present work, a superhydrophobic glass surface comprising zinc oxide nanotriangles (ZnO-nt) and nontoxic silylating agent was developed via a cost-effective spray-coating technology. ZnO-nt was synthesized by a hydrothermal method. Poly(dimethylsiloxane) (PDMS) and dimethyldiethoxysilane (DMDEOS) were used as nontoxic (nonfluoro) silylating agents. The morphology and crystallinity of $\mathrm{ZnO}$-nt were studied using X-ray diffraction (XRD) and transmission electron microscopy (TEM) techniques. ZnO-nt with polymeric silane (PDMS) exhibited maximum wettability as compared to nonpolymeric silane (DMDEOS). The water contact angle (WCA), sliding angle (SA), and surface roughness of ZnO-nt/PDMS-coated glass substrate under UV treatment were $165 \pm 1^{\circ}, 3 \pm 1^{\circ}$, and $791 \mathrm{~nm}$, respectively. The WCA of ZnO-nt/PDMS was higher $\left(165^{\circ}\right)$ than that of commercial $\mathrm{ZnO} / \mathrm{PDMS}$ (ZnO-C/PDMS). ZnO-nt/PDMS was strongly attached to the glass substrate with good stability and adhesion. The reasons for improved hydrophobicity, adhesion, and mechanism of hierarchical microstructure formation on the glass substrate were explained in detail. PDMS was attached to the glass substrate via hydrogen bonds from solvated zinc acetate.
\end{abstract}

\section{Introduction}

In recent years, there is tremendous interest for surfaces that are extremely repellent to water droplets. The minimal contact of water on such surfaces makes them appealing for a variety of applications such as self-cleaning [1], anti-icing [2], anticorrosion [3], water harvesting [4], and antibacterial coating [5]. These surfaces are called as superhydrophobic with a water contact angle (WCA) higher than $150^{\circ}$ and a sliding angle (SA) lower than $10^{\circ}$ [6]. The following conditions are necessary to fabricate a superhydrophobic surface: (i) creation of hierarchical rough surface [7] and (ii) chemical modification of rough surface with low surface energy materials [8]. The most popular methods to create superhydrophobic surfaces are plasma etching [9], sol-gel [10], electrospinning [11], layer by layer assembly [12], phase separation [13], and solution immersion [14]. However, the feasibility of these methods for real applications is limited by the following factors: time-consuming, sophisticated instruments, and using of expensive and toxic fluorosilanes. Therefore, the recent research works have been focused on the fabrication of superhydrophobic surfaces using inexpensive raw materials, nontoxic surface modifiers, and convenient spray-coating technique. Moreover, spray coating is a convenient technique for ready-made applications such as construction and building applications.

Table 1 summarizes the results of various superhydrophobic coatings produced by spray-coating technique, nanoparticles $\left(\mathrm{ZnO}, \mathrm{SiO}_{2}, \mathrm{TiO}_{2}\right.$, and colloidal zinc hydroxide) [15-21], and nonfluorinated silylating agents. Among the various metal oxide nanoparticles, $\mathrm{ZnO}$ is widely used to fabricate a rough surface [22-24]. The synthesis of $\mathrm{ZnO}$ 


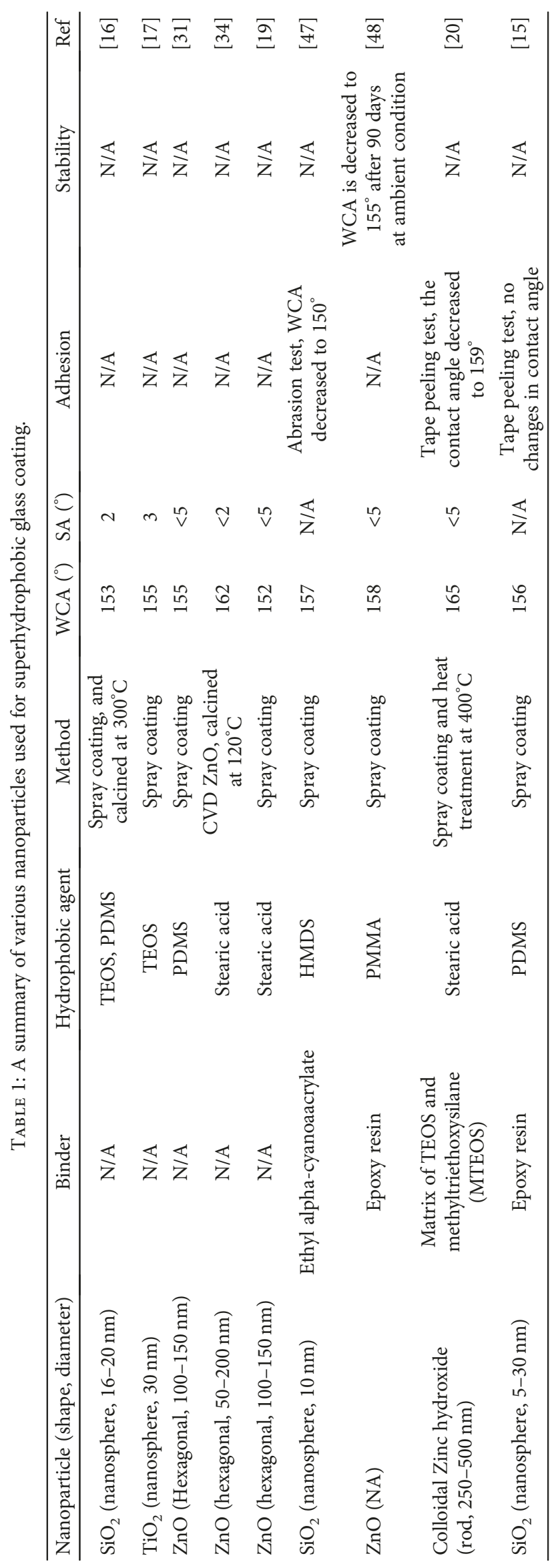


in various dimensions $(0 \mathrm{D}, 1 \mathrm{D}, 2 \mathrm{D}$, and $3 \mathrm{D})$ via precipitation, sol-gel, hydrothermal, solvothermal, and microwave irradiation methods has also triggered considerable interest to investigate the effect of morphology on superhydrophobicity [25-28]. Nevertheless, the superhydrophobicity of $\mathrm{ZnO}$ with nanotriangle morphology ( $\mathrm{ZnO}-\mathrm{nt}$ ) has not been reported. Furthermore, $\mathrm{ZnO}$ is generally regarded as a safe material to human beings and animals [29]. It also has numerous applications in industries, cosmetics, and medical devices $[5,30]$.

Eco-friendly hydrophobic coatings with high WCA were also attained by non-fluoromaterials with low surface energy such as stearic acid, dimethyldiethoxysilane (DMDEOS), methyltriethoxysilane (MTEOS), hexamethyldisilazane (HMDS), poly(methyl methacrylate) (PMMA), and poly(dimethylsiloxane) (PDMS). Among these surface modifiers, polymeric silylating agents (such as PDMS) have extra advantages such as chemical stability, mechanical elasticity, long endurance, and attractive transparency for outdoor applications $[20,31,32]$. Furthermore, PDMS has the capability to reduce the surface free energy of the coating within a short period [31].

Several groups have developed superhydrophobic coatings using $\mathrm{ZnO}$ and PDMS but only few of them tried to solve the poor adhesion of these materials on the glass surface $[31,33]$. The main reason for the poor adhesion and mechanical strength is the lack of necessary hydrogen-bonding interactions between the glass surface and the hydrophobic mixture (silylating agent/ZnO). Few reports are available on the use of complex techniques, binder, epoxy, or additional heat treatment to form a strong bond between the coating and the substrate. For example, Li et al. reported the superhydrophobicity of $\mathrm{ZnO}$ with stearic acid. The surface was fabricated by spray coating followed by chemical vapour deposition technique. The coating fabricated via this method possessed an excellent superhydrophobicity, nevertheless the process involved multiple steps. Besides, the stability and adhesion of the coating were not reported [34]. Chakradhar et al. [31] studied the superhydrophobicity of $\mathrm{ZnO}-\mathrm{PDMS}$ through a facile spray-coating method. The usage of primes (epoxy) as a binder was a prerequisite to improve the adhesion of the coating. Das et al. [8] examined the fabrication of robust superhydrophobic surface on glass using $\mathrm{ZnO}$ at high temperature curing $\left(400^{\circ} \mathrm{C}\right)$. Simovich et al. [35] fabricated a robust superhydrophobic surface by the combination of epoxy resin, hexamethylenediamine, and silica nanoparticles. Nevertheless, the hydrophobic solution was maintained at a temperature in the range of $70-80^{\circ} \mathrm{C}$, the substrate was heated to $150^{\circ} \mathrm{C}$ prior to spraying process, and then it was cured at $130^{\circ} \mathrm{C}$ for $24 \mathrm{~h}$. All these techniques with high temperature curing and multiple steps are not favorable for industrial applications.

Therefore, in this present work, the superhydrophobicity of $\mathrm{ZnO}$-nt with nonfluorinated silanes such as hydroxyterminated PDMS (long-chain polymeric silylating agent) and DMDEOS (short-chain nonpolymeric silylating agent) was studied by spray-coating technique. The existence of solvated $\mathrm{Zn}$ acetate as a minor impurity could promote the bonding interactions between the glass substrate and

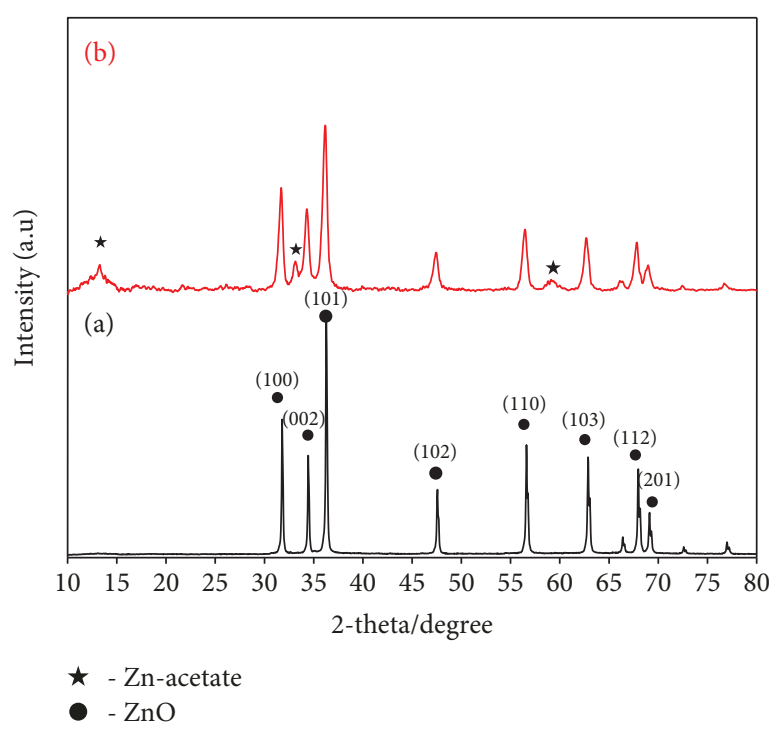

Figure 1: XRD patterns of (a) $\mathrm{ZnO}-\mathrm{C}$ and (b) $\mathrm{ZnO}$-nt.

hydrophobic mixture The superhydrophobicity of commercial $\mathrm{ZnO}(\mathrm{ZnO}-\mathrm{C})$ was also studied for reference.

\section{Experimental}

2.1. Materials. Zinc acetate dihydrate $\left(\mathrm{Zn}\left(\mathrm{CH}_{3} \mathrm{COO}\right)_{2} \cdot 2 \mathrm{H}_{2} \mathrm{O}\right.$, 99.8\%), dimethyldiethoxysilane (DMDEOS, 98\%), hydroxyterminated poly(dimethylsiloxane) (PDMS), commercial zinc oxide (ZnO-C, 99.0\%), acetic acid (98\%), and sulphuric acid $(97 \%)$ were purchased from Sigma-Aldrich. Ethanol (99\%), isopropanol (98\%), and n-hexane (98\%) were purchased from Merck Millipore. All the chemicals used were of AR grade and used as received without further purification. The plain microscopy glass slides were supplied by Fisher Scientific.

2.2. Synthesis of $\mathrm{ZnO}$ Nanotriangle ( $\mathrm{ZnO}-\mathrm{nt}$ ). $\mathrm{ZnO}-\mathrm{nt}$ was synthesized using a hydrothermal method [36]: 0.1 M of zinc acetate dihydrate solution was prepared using ethanol. Then, the $\mathrm{pH}$ was adjusted to 3 using acetic acid and the solution was stirred for $3 \mathrm{~h}$ at room temperature. The final mixture was transferred into a Teflon-coated stainless steel autoclave and was heated at $120^{\circ} \mathrm{C}$ for $5 \mathrm{~h}$. The product was centrifuged and washed one time with deionized water. To preserve the content of unreacted zinc acetate, further washing procedures with water or alcohol were not performed. The final product was dried at $100^{\circ} \mathrm{C}$ for $24 \mathrm{~h}$ in an air oven.

\subsection{Synthesis of Hydrophobic Mixture}

2.3.1. $\mathrm{ZnO}-n \mathrm{t} / \mathrm{DMDEOS}$. $50 \mathrm{ml}$ of isopropanol, $3.5 \mathrm{ml}$ of $1 \mathrm{M}$ $\mathrm{H}_{2} \mathrm{SO}_{4}, 1 \mathrm{ml}$ of deionized water, and $15 \mathrm{ml}$ of DMDEOS were vigorously stirred for $30 \mathrm{~min}$. This mixture was labelled as sol A. Simultaneously, $7 \mathrm{wt} \%$ of $\mathrm{ZnO}-\mathrm{nt}$ was dispersed in a mixture of isopropanol $(50 \mathrm{ml}), 1 \mathrm{M} \mathrm{H}_{2} \mathrm{SO}_{4}(3.5 \mathrm{ml})$, and deionized water $(1 \mathrm{ml})$. This mixture was labelled as sol $\mathrm{B}$. The superhydrophobic solution was prepared by adding sol B into the sol A drop wisely under constant stirring. 


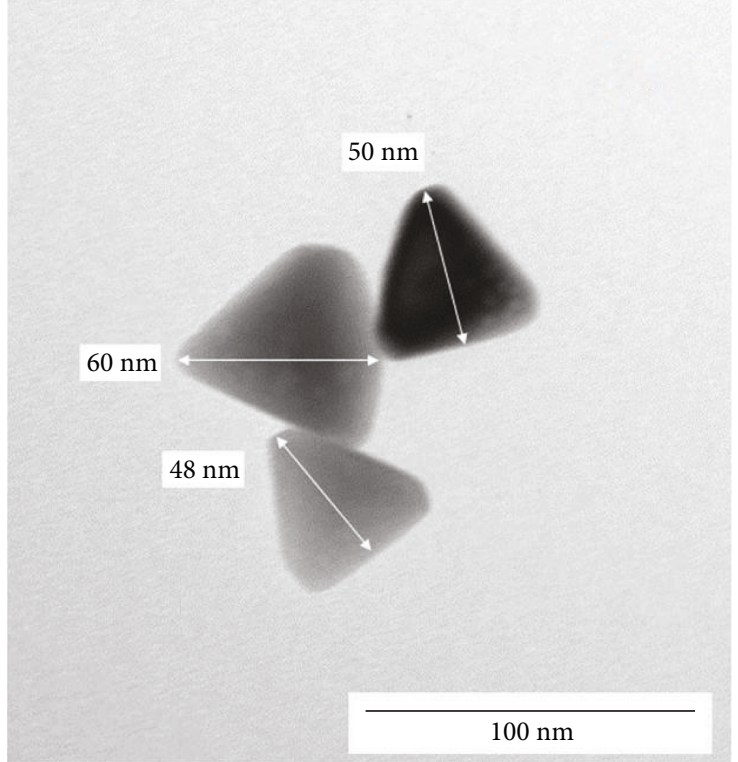

(a)

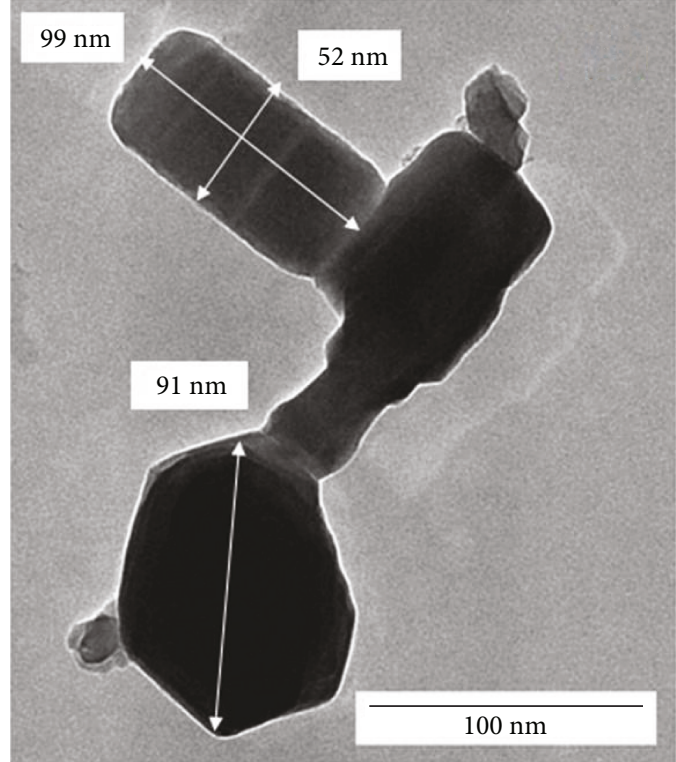

(b)

Figure 2: TEM images of (a) ZnO-nt and (b) ZnO-C.

2.3.2. $\mathrm{ZnO}-n t / P D M S$. $2.52 \mathrm{~g}$ of PDMS was dissolved in $50 \mathrm{ml}$ of $\mathrm{n}$-hexane and stirred vigorously for $30 \mathrm{~min} .7 \mathrm{wt} \%$ of $\mathrm{ZnO}-$ nt was dispersed in PDMS solution and further stirred magnetically for $30 \mathrm{~min}$. For comparison, $\mathrm{PDMS}$ with $\mathrm{ZnO}-\mathrm{C}$ was also prepared.

\subsection{Fabrication of $\mathrm{ZnO}-\mathrm{nt} / \mathrm{DMDEOS}$ and $\mathrm{ZnO}-\mathrm{nt} / \mathrm{PDMS}$} Coatings. The glass substrate was ultrasonically cleaned in acetone for $10 \mathrm{~min}$ followed by rinsing with deionized water for $5 \mathrm{~min}$. Then, the coating mixture was applied on the glass substrate using an airbrush (IWATA) with a $1.5 \mathrm{~mm}$-diameter nozzle. The atomizing air pressure was maintained at $40 \mathrm{psi}$. The distance between the airbrush and the substrate was kept at $10 \mathrm{~cm}$. The airbrush was moved laterally back and forth to make a uniform coating on the glass substrate. The coated glass substrate was dried at $80^{\circ} \mathrm{C}$ for $5 \mathrm{~min}$ in an oven. This procedure was repeated for 5 times with a time interval of $5 \mathrm{~min}$. The glass substrate was allowed to cure at $80^{\circ} \mathrm{C}$ for $12 \mathrm{~h}$. Finally, the dried glass substrates were exposed to UV irradiation ( $254 \mathrm{~nm}, 36 \mathrm{~W}$ germicidal lamp) for $48 \mathrm{~h}$. Based on our preliminary work, UV exposure is beneficial to create a tightly packed structure due to the photooxidation of organic compounds [21].

2.5. Stability Test. Acid-base resistance is one of the important factors that would increase the widespread practical applications of hydrophobic coatings. To evaluate the acidbase resistance, an experiment was conducted by immersing the hydrophobic coated glass substrate in solutions with different $\mathrm{pH}(4,7$, and 10$)$ for 100 days. The $\mathrm{pH}$ values were selected by considering the $\mathrm{pH}$ of washing solution (9-11) [37], tap water/deionized water (6-7), and acid rain (4) [38]. WCA was measured after an immersion period of 100 days in the desired $\mathrm{pH}[39]$.

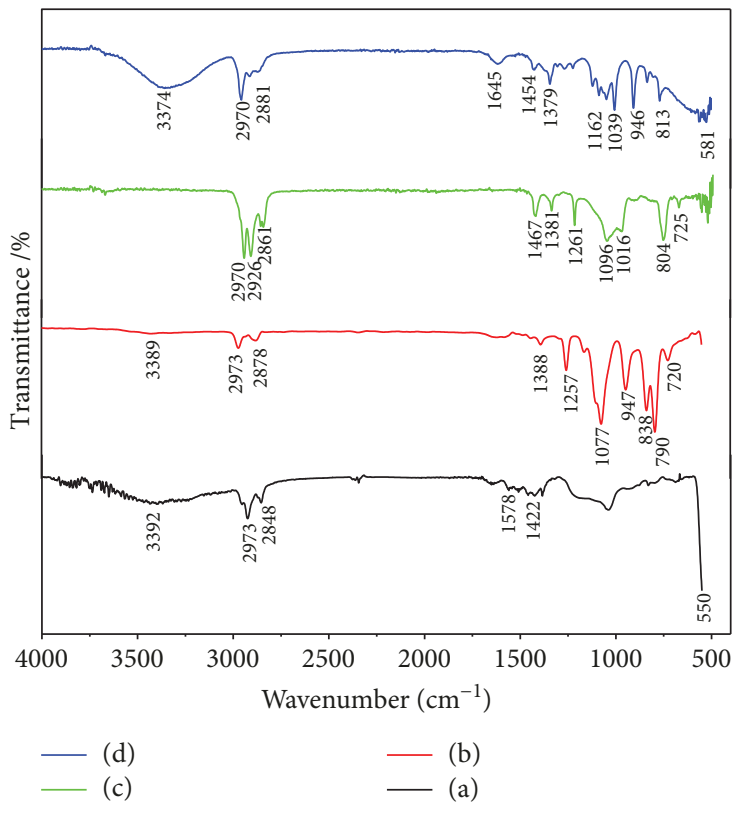

Figure 3: FTIR spectrum of (a) ZnO-nt, (b) DMDEOS, (c) PDMS, and (d) $\mathrm{ZnO}-\mathrm{nt} / \mathrm{PDMS}$

2.6. Adhesion Test. Peel-off tape test was used to determine the adherence of hydrophobic coating. As reported, at the expense of adherence functionalization and micro-/nanosurface roughness, the primary function of $\mathrm{ZnO}$-nt is to deliver the hydrophobicity through its functionalization with PDMS [31]. The peel-off adhesion test was carried out using a cellophane tape. The tape was laid across the coated surface and rubbed vigorously to ensure a good contact with the coating, then slowly pulled away from the sample at about $45^{\circ}$ to the surface, and this process was repeated for 10 times at the same place using a new tape [40]. 

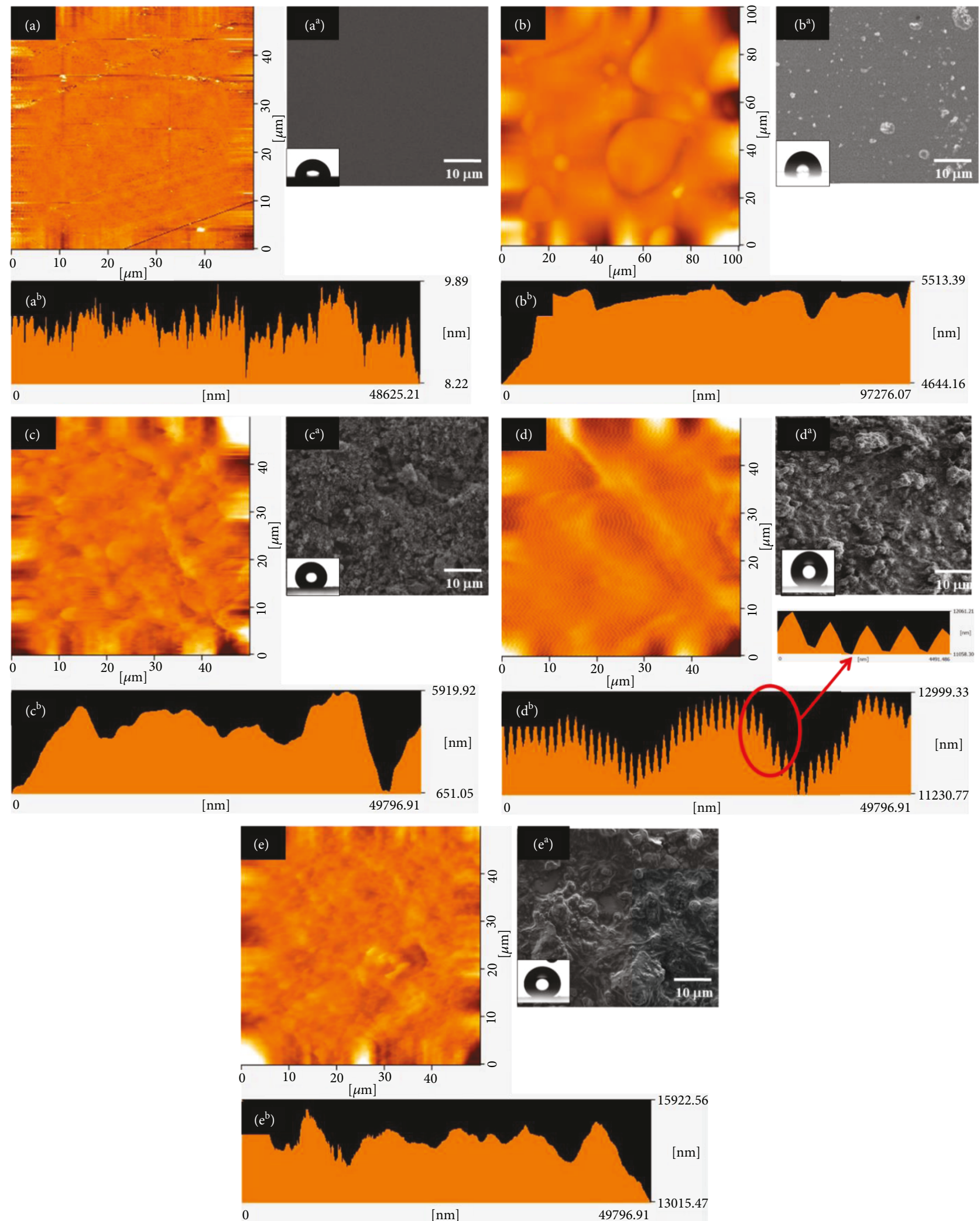

FIgURe 4: 2D AFM images of (a) bare glass, (b) DMDEOS, (c) PDMS, (d) ZnO-nt/PDMS, and (e) ZnO-C/PDMS coated-glass. ( $a^{\mathrm{a}}, \mathrm{b}^{\mathrm{a}}, \mathrm{c}^{\mathrm{a}}, \mathrm{d}^{\mathrm{a}}$, and $\mathrm{e}^{\mathrm{a}}$ ) The FE-SEM images of corresponding samples; $\left(\mathrm{a}^{\mathrm{b}}, \mathrm{b}^{\mathrm{b}}, \mathrm{c}^{\mathrm{b}}, \mathrm{d}^{\mathrm{b}}\right.$, and $\left.\mathrm{e}^{\mathrm{b}}\right)$ the AFM line profile; the red arrow shows the narrow scan of AFM line profile of $\mathrm{ZnO}-\mathrm{nt} / \mathrm{PDMS}$. 
2.7. Characterization. The functional groups of glass substrates were confirmed by a Fourier-transform infrared spectrometer (FTIR, Tensor27, Bruker, Germany). The crystalline properties were characterized using an X-ray diffraction (XRD) with $\mathrm{Cu} \mathrm{K} \alpha$ radiation $(\lambda=0.1542 \mathrm{~nm})$ operated at $40 \mathrm{kV}$ and $40 \mathrm{~mA}$. The morphology of $\mathrm{ZnO}-\mathrm{nt}$ was studied with the help of a transmission electron microscopy (TEM, TEM; H-7600, Hitachi) and a field emission scanning electron microscopy (FESEM-EDX, Zeiss, Supra 35VP). The surface topology was characterized using an atomic force microscopy (AFM, NanoNavi, SPA400) operated in contact mode. The root mean square (RMS) of the hydrophobic coating was calculated according to the following equation:

$$
\mathrm{RMS}=\sqrt{\frac{\sum_{i=1}^{N}\left(Z_{i}-Z_{a v}\right)^{2}}{N}}
$$

where $Z_{a v}$ is the average height for the entire region, $Z_{i}$ is the height of individual point $i$, and $N$ is the number of points measured within the given area. The water contact angle (WCA), surface energy, and sliding angle were measured with a droplet volume of $5 \mu \mathrm{L}$ using a goniometer (Rame-Hart Instrument. Co, USA) on one side of the sample (sessile drop method). DROPimage Advanced software was used to analyze the data. Briefly, the glass substrates were placed in a contact angle goniometer, attached to an image analyzer. Each sample was subjected to 10 measurements in 4-angle positions: vertical left, vertical right, horizontal left, and horizontal right.

\section{Results and Discussion}

3.1. XRD. The crystalline phases of $\mathrm{ZnO}-\mathrm{C}$ and $\mathrm{ZnO}-\mathrm{nt}$ are shown in Figure 1. The major diffraction peaks of $\mathrm{ZnO}-\mathrm{C}$ and $\mathrm{ZnO}$-nt are perfectly matched with the standard JCPDS pattern (36-1451) [36]. For $\mathrm{ZnO}$-nt, some additional peaks are detected at $2 \theta$ of $13.21^{\circ}, 33.11^{\circ}$, and $59.26^{\circ}$. This is ascribed to the existence of unreacted zinc acetate dihydrate (JCDPS no. 01-0089) in low concentration, based on The Rietveld refinement of the compound has confirmed that, $\mathrm{ZnO}-\mathrm{nt}$ contained $73 \%$ of $\mathrm{ZnO}$ and $27 \%$ of $\mathrm{Zinc}$ acetate. This is beneficial to induce hydrogen bonding and promotes the interaction between glass substrate and hydrophobic mixture. The average crystallite sizes were determined using the DebyeScherrer equation. The average crystallite sizes were found to be $51 \mathrm{~nm}$ and $34 \mathrm{~nm}$ for $\mathrm{ZnO}-\mathrm{C}$ and $\mathrm{ZnO}-\mathrm{nt}$, respectively.

3.2. TEM. TEM micrographs of $\mathrm{ZnO}-\mathrm{C}$ and $\mathrm{ZnO}-\mathrm{nt}$ are shown in Figure 2. Figure 2(a) confirms the formation of $\mathrm{ZnO}$ nanotriangles with diameter in the range of $45-60 \mathrm{~nm}$. $\mathrm{ZnO}-\mathrm{C}$ consists of a mixture of irregular hexagonal and rectangular particles (Figure 2(b)). The average diameter of rectangle/hexagonal particle is in the range of $90-100 \mathrm{~nm}$ (Figure 2(b)). TEM results revealed that the nanotriangles are smaller when compared to hexagonal or rectangular particles. The small size of $\mathrm{ZnO}$-nt would display high surface energy, which makes it thermodynamically unstable or
TABLE 2: WCA, SA, and water drop behavior of glass substrate coated with different hydrophobic mixtures.

\begin{tabular}{lccc}
\hline Substrate & WCA $\left(^{\circ}\right)$ & SA $\left(^{\circ}\right)$ & Water drop behavior \\
\hline Bare glass & $44 \pm 2$ & - & Wetted \\
DMDEOS & $72 \pm 2$ & - & Wetted \\
PDMS & $134 \pm 2$ & $12 \pm 1$ & Pinned \\
ZnO-nt/PDMS & $165 \pm 1$ & $3 \pm 1$ & Roll off \\
ZnO-C/PDMS & $153 \pm 2$ & $5 \pm 1$ & Pinned \\
\hline
\end{tabular}

metastable as compared to $\mathrm{ZnO}-\mathrm{C}$ [41]. Consequently, $\mathrm{ZnO}$-nt is highly beneficial to fabricate a hierarchical structure with low surface energy and improved hydrophobicity.

3.3. FT-IR. FT-IR spectra of ZnO-nt, DMDEOS, PDMS, and $\mathrm{ZnO}-\mathrm{nt} / \mathrm{PDMS}$ are shown in Figure 3. For $\mathrm{ZnO}-\mathrm{nt}$ (Figure 3(a)), the peak observed at $3392 \mathrm{~cm}^{-1}$ is attributed to $\mathrm{O}-\mathrm{H}$ stretching vibration of adsorbed water on the $\mathrm{ZnO}$ surface [31]. A strong peak noticed at $\sim 500 \mathrm{~cm}^{-1}$ is ascribed to $\mathrm{Zn}-\mathrm{O}$ stretching vibration [42]. The additional absorption bands identified at $2973 \mathrm{~cm}^{-1}$ and $2848 \mathrm{~cm}^{-1}$ are attributed to $\mathrm{CH}_{3}$ and $\mathrm{C}-\mathrm{H}$ band, respectively, which might be resulting from the acetate precursor [43]. The existence of bands near $1578 \mathrm{~cm}^{-1}$ and $1422 \mathrm{~cm}^{-1}$ is associated with the $\mathrm{C}=\mathrm{O}$ stretching vibration of the acetate group [8], indicating the presence of acetate, which is deduced to be the possible functional group to anchor with silanol group of glass substrate.

For DMDEOS (Figure 3(b)), the band observed at $3389 \mathrm{~cm}^{-1}$ is ascribed to the $\mathrm{OH}$ group, indicating that the silane group of DMDEOS is hydrolyzed by acid [44]. Two peaks centered at $2973 \mathrm{~cm}^{-1}$ and $1257 \mathrm{~cm}^{-1}$ are attributed to $\mathrm{CH}_{3}$ stretching and bending vibrations from DMDEOS. The bands located at $1077 \mathrm{~cm}^{-1}, 838 \mathrm{~cm}^{-1}$, and $790 \mathrm{~cm}^{-1}$ are assigned to the $\mathrm{Si}-\mathrm{O}-\mathrm{Si}, \mathrm{Si}-\mathrm{C}$, and $\mathrm{Si}-\mathrm{O}$ vibrations, respectively [16].

For PDMS (Figure 3(c)) and ZnO-nt/PDMS (Figure 3(d)), the peaks are almost similar. An additional peak observed at $3374 \mathrm{~cm}^{-1}$ for $\mathrm{ZnO}-\mathrm{nt} / \mathrm{PDMS}$ is associated to the $\mathrm{OH}$ group at the $\mathrm{ZnO}$ surface [31]. Two strong peaks observed at $2970 \mathrm{~cm}^{-1}$ and $2881 \mathrm{~cm}^{-1}$ are ascribed to antisymmetric and symmetric $-\mathrm{CH}_{3}$ stretching, confirming the presence of $\mathrm{Si}-\left(\mathrm{CH}_{3}\right)_{3}$ and $\mathrm{Si}-\mathrm{O}-\mathrm{CH}_{3}$ groups [23]. A series of absorption peaks in the range of $600 \mathrm{~cm}^{-1}-2000 \mathrm{~cm}^{-1}$ are ascribed to the vibrations of various silane groups ( $\mathrm{Si}-\mathrm{O}$ in $\mathrm{Si}-\mathrm{O}-\mathrm{Si}$ backbone and $\mathrm{Si}-\mathrm{CH}_{3}$ ) on the $\mathrm{ZnO}-\mathrm{nt} / \mathrm{PDMS}$ surface [16]. A weak peak located at $946 \mathrm{~cm}^{-1}$ is attributed to $\mathrm{Zn}-\mathrm{O}$ $\mathrm{Si}$, confirming the reaction between zinc acetate and the residual silanol (Si-OH) group (at $804 \mathrm{~cm}^{-1}$ in Figure $3(\mathrm{c})$ ) [8]. The hydrophobic properties of a coating are greatly influenced by the existence of methyl groups [38, 45]. FTIR analysis affirms the presence of more methyl groups in $\mathrm{ZnO}$-nt/PDMS as compared to $\mathrm{ZnO}$-nt/DMDEOS. Thus, it can be inferred that PDMS is a more prominent silylating agent to attain maximum hydrophobicity.

3.4. Surface Roughness and Wettability. 2D topographic mapping, FE-SEM and AFM line profile images of bare glass, DMDEOS, PDMS, ZnO-nt/PDMS, and $\mathrm{ZnO}-\mathrm{C} / \mathrm{PDMS}-$ 


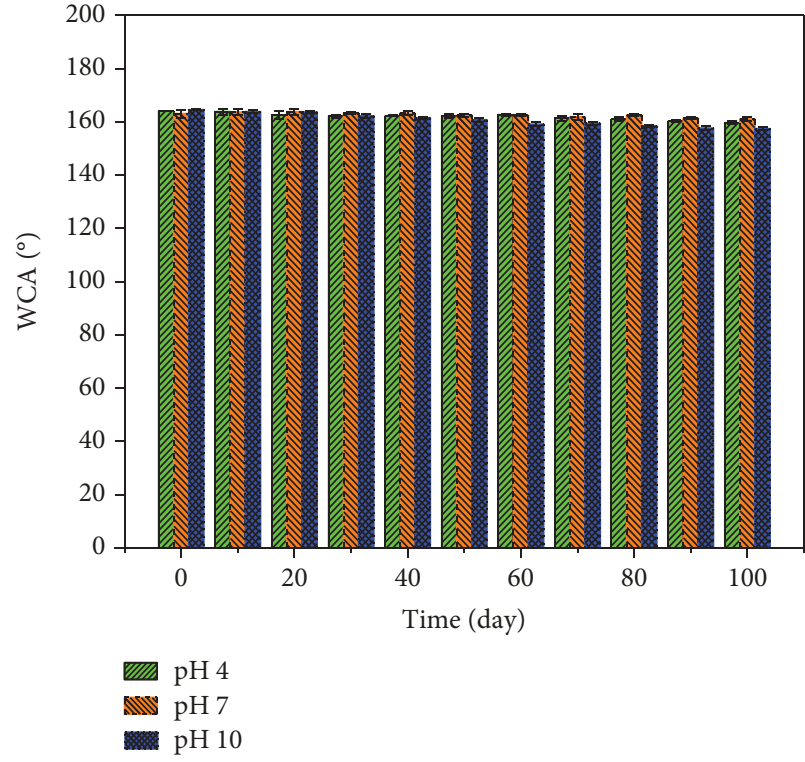

(a)

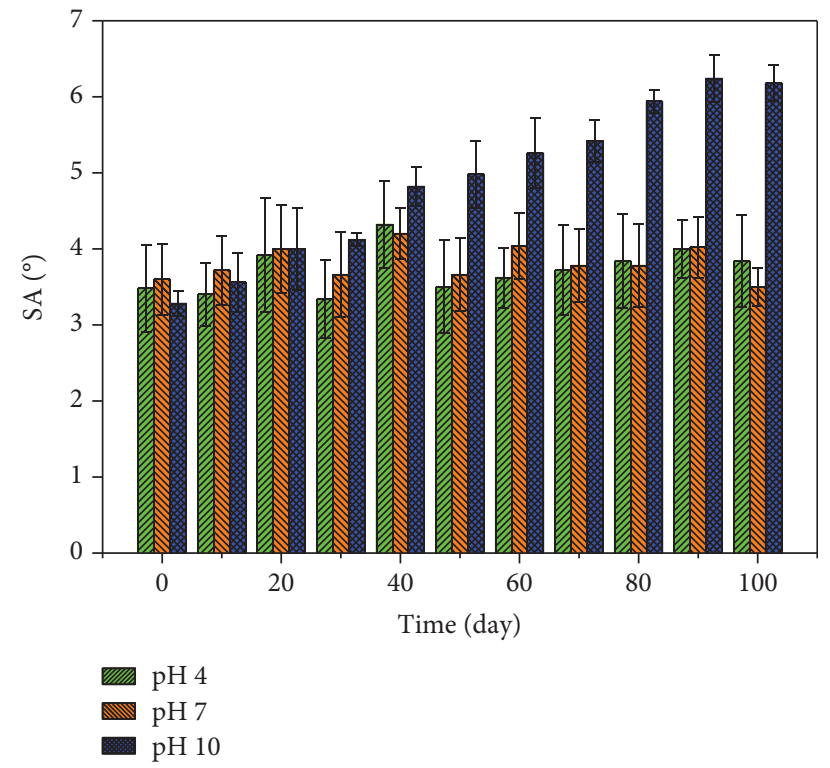

(b)

Figure 5: WCA (a) and SA (b) of ZnO-nt/PDMS-coated and UV-cured glass substrates at various pH after 90 days. Error bars are the standard deviation of the contact angles from five repeating tests.
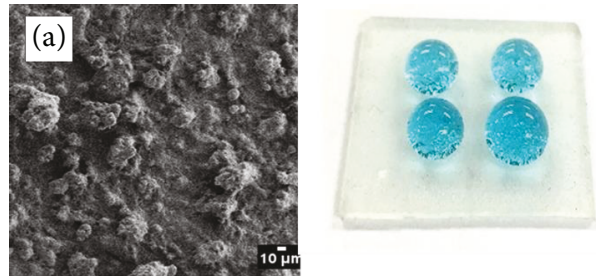

(a)
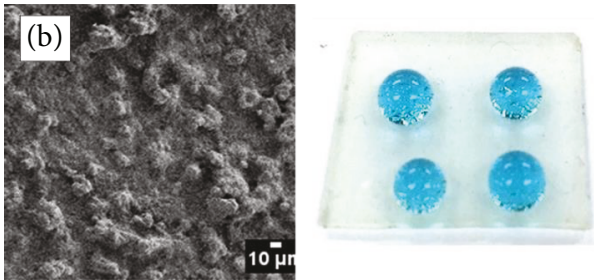

(b)

FIGURE 6: FESEM image and photograph (appearance of $10 \mu \mathrm{L}$ water droplet on the glass surface) of ZnO-nt/PDMS-coated and UV-cured glass substrate (a) before and (b) after 10 peel-off tape tests.

coated glass substrates are shown in Figure 4. WCA, SA, and water drop behavior are tabulated in Table 2. Bare glass has a uniform and smooth surface (Figure $4\left(\mathrm{a}^{\mathrm{a}}\right)$ ) with a $R_{a} /$ RMS value of about $310 \mathrm{~nm}$ (Figure 4(a)) and WCA of $44 \pm 2^{\circ}$, indicating the hydrophilic nature. After coating with DMDEOS, the $R_{a} / \mathrm{RMS}$ roughness is increased to $410 \mathrm{~nm}$ (Figure $4(\mathrm{~b})$ ) with a WCA of $72 \pm 2^{\circ}$. FE-SEM (Figure $4\left(\mathrm{~b}^{\mathrm{a}}\right)$ ) and AFM line profile (Figure $4\left(\mathrm{~b}^{\mathrm{b}}\right)$ ) images reveal that the surface roughness of a glass is increased by the addition of DMDEOS. Similarly, when coated with PDMS, the WCA is increased to $134 \pm 2^{\circ}$ with a $R_{a} / \mathrm{RMS}$ roughness of $589 \mathrm{~nm}$ (Figure $4(\mathrm{c})$ ). The results are in good agreement with the FE-SEM image (Figure $4\left(c^{\mathrm{a}}\right)$ ) and AFM line profile (Figure $4\left(c^{b}\right)$ ), which reveals a rough surface with cavities. It is also noted that the chemical mixture with low surface energy plays a major role in improving the hydrophobicity. PDMS has low surface energy $(7.16 \mathrm{~N} / \mathrm{m})$ as compared to DMDEOS $(40.44 \mathrm{~N} / \mathrm{m})$. Besides, PDMS has a long chain of ( $\left.\mathrm{Si}-\left(\mathrm{CH}_{3}\right)_{2}-\mathrm{O}-\right)$ group and sterically closed structure. Thus, it minimizes the Van der Waals contact and enhances the hydrophobic behavior. ZnO-nt/PDMS-coated glass substrate exhibits a maximum WCA of $165 \pm 1^{\circ}$ with a surface roughness of $791 \mathrm{~nm}$ (Figure $4(\mathrm{~d})$ ). More protrusions are

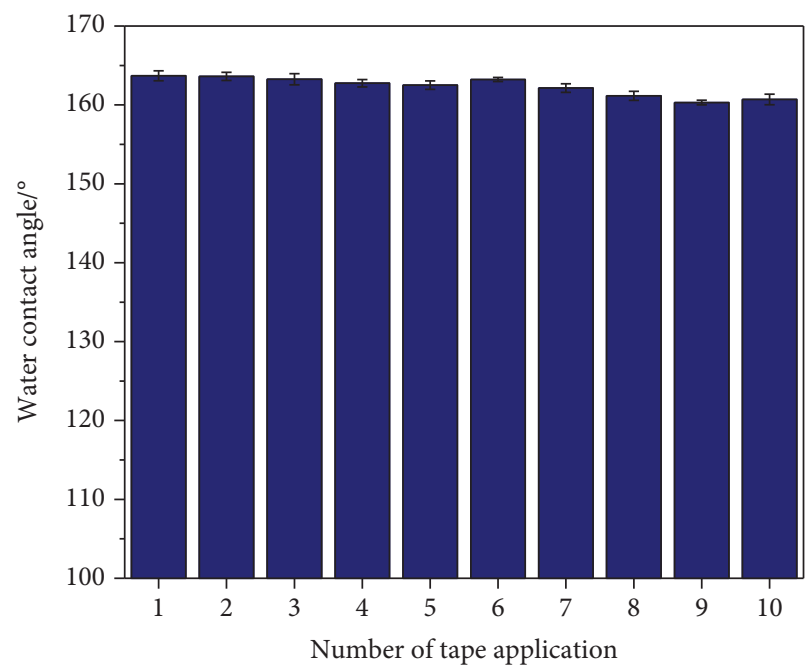

FigURE 7: WCA of ZnO-nt/PDMS-coated glass substrate during 10 peel-off tape tests. Error bars are the standard deviation of the contact angles from five repeating tests. 
$\mathrm{Zn}\left(\mathrm{CH}_{3} \mathrm{COO}\right)_{2} \cdot 2 \mathrm{H}_{2} \mathrm{O}+\mathrm{CH}_{3} \mathrm{CH}_{2} \mathrm{OH} \longrightarrow$ Solvated zinc acetate $+\mathrm{ZnO}$

(a)

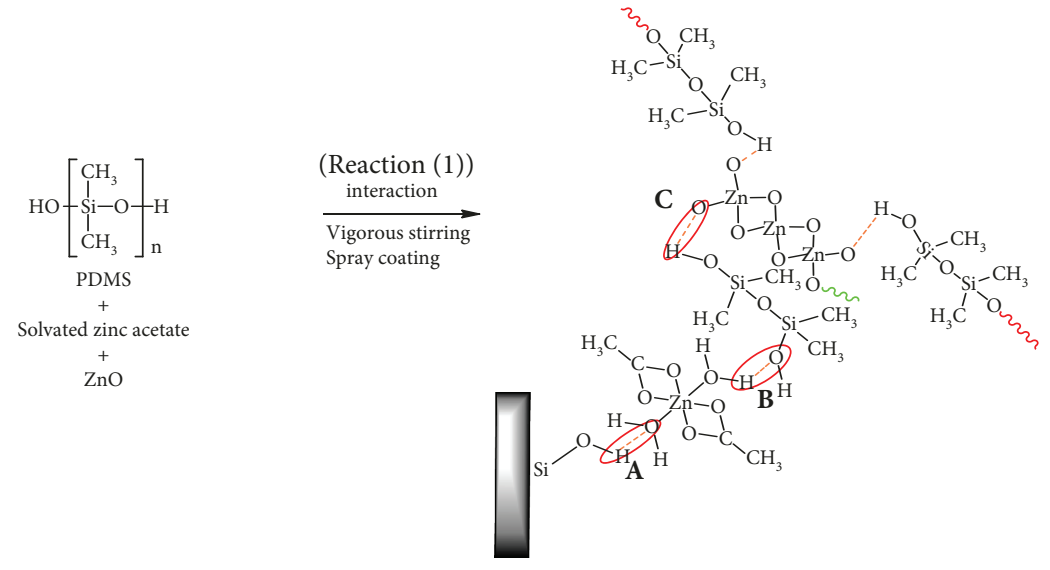

(b)

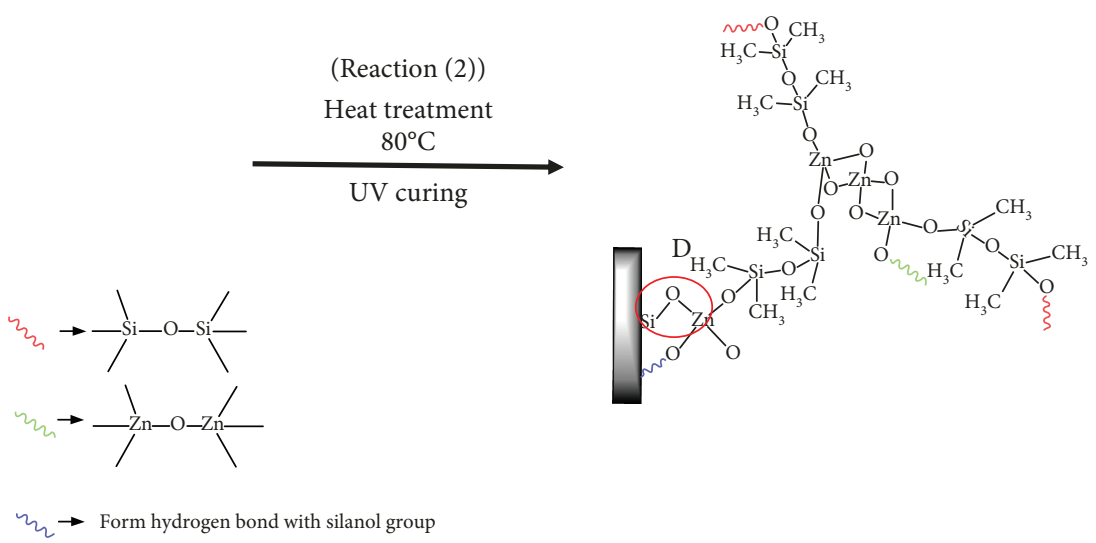

(c)

FIgURE 8: The proposed schematic representation for the formation of ZnO-nt/PDMS-coated superhydrophobic film: (a) referring to the molecular structure of the solvated zinc acetate after the hydrothermal process which contains $-\mathrm{H}$ and $-\mathrm{O}$ groups; (b) reaction between solvated zinc acetate and PDMS which resulted in the formation of hydrogen bond with the glass surface (marked as A) and PDMS (marked as B) and the formation of hydrogen bond between the $-\mathrm{O}$ group from tetrahedral $\mathrm{ZnO}$ with the $-\mathrm{H}$ group of PDMS (marked as $\mathrm{C}$ ); and (c) after spray-coating and heat treatment, Si-O-Zn linkage (marked as D) is formed on the glass surface.

observed for $\mathrm{ZnO}-\mathrm{nt} / \mathrm{PDMS}$ (Figure $4\left(\mathrm{~d}^{\mathrm{a}}\right)$ ) when compared to pure PDMS. This can be described as microscale $\mathrm{ZnO}$ nt/PDMS globules (Figure $4\left(\mathrm{~d}^{\mathrm{b}}\right)$ ) which consist of nanoscale $\mathrm{ZnO}-\mathrm{nt}$ (inset Figure $4\left(\mathrm{~d}^{\mathrm{b}}\right)$ ). This hierarchical structure produces an intrinsic multiscale roughness that is necessary for superhydrophobicity with high WCA and low SA. Moreover, the high concentration of $-\mathrm{CH}_{3}$ and $-\mathrm{Si}-\left(\mathrm{CH}_{3}\right)_{3}$ groups (Figure 3) further improves the superhydrophobicity.

The $\mathrm{ZnO}-\mathrm{C} / \mathrm{PDMS}$-coated glass substrate displays a low WCA $\left(153 \pm 2^{\circ}\right)$ when compared to ZnO-nt/PDMS. The $R_{a}$ $/ \mathrm{RMS}$ roughness is $658 \mathrm{~nm}$ (Figure 4(e)). The FE-SEM image of $\mathrm{ZnO}-\mathrm{C} / \mathrm{PDMS}$ shows the presence of microscale globules (Figure $4\left(e^{\mathrm{a}}\right)$ ). As compared to $\mathrm{ZnO}-\mathrm{nt} / \mathrm{PDMS}$, the AFM line profile (Figure $4\left(\mathrm{e}^{\mathrm{b}}\right)$ ) of $\mathrm{ZnO}-\mathrm{C} / \mathrm{PDMS}$ shows less surface texture without multiscale roughness.

The wetting behavior of $\mathrm{ZnO}-\mathrm{C} / \mathrm{PDMS}$ and $\mathrm{ZnO}-\mathrm{nt} /$ PDMS can be explained by the Wenzel and Cassie-Baxter state, respectively [46]. In the Wenzel state, water droplets are entrapped in the voids and pinned tightly on the rough surface, while in the Cassie-Baxter state, the water droplets are suspended on the top asperities of the rough surface due to entrapped air cushions in the cavities. In order to understand the wetting behavior of $\mathrm{ZnO}-\mathrm{nt} / \mathrm{PDMS}$ and $\mathrm{ZnO}-\mathrm{C} / \mathrm{PDMS}$, water drop behavior is recorded and the results are presented in Table 2 . The water droplet that was dragged across the $\mathrm{ZnO}$-nt/PDMS surface was not blocked in any way and started to roll over at a SA of $3 \pm 1^{\circ}$. The water droplet was able to roll away completely at a SA of $5 \pm 1^{\circ}$, suggesting that the coated surface is in a Cassie-Baxter state. This phenomenon is mainly attributed to a surface that mainly composed of mountains like protrusions (Figure $4\left(\mathrm{~d}^{\mathrm{a}}\right)$ ) and closely packed 3D hierarchical network. In contrast, the water droplet was highly pinned when it was dragged over the $\mathrm{ZnO}-\mathrm{C} / \mathrm{PDMS}$ surface. The pinning effect supports a Wenzel state. Lack of protrusions and rough surface (Figure $4\left(e^{a}\right)$ ) allows the water droplet to easily penetrate into the chemically modified surface, leading to the enlargement of contact area between the water drop and glass surface. 
3.5. Stability Test. Figure 5 displays the relationship between $\mathrm{pH}$ and hydrophobicity (WCA (Figure 5(a)) and SA (Figure 5(b))) of ZnO-nt/PDMS-coated glass substrate. There is no remarkable change in the WCA at $\mathrm{pH} 7$ and 4 [18]. These results confirm that the coating has a strong tolerance to acid rain and tap water and sustain the rolling properties. However, the WCA is slightly decreased at $\mathrm{pH} 10$, and SA is increased from $3^{\circ}$ to $6^{\circ}$, indicating the alkaline solution can corrode the superhydrophobic coating. This is mainly ascribed to the dissolution of $\mathrm{ZnO}$ at high alkaline $\mathrm{pH}[39]$.

3.6. Peel-Off Tape Test. The adherence of the coating was assessed according to Cholewinski et al.'s [15] work (peeloff tape test at 4 tape applications). In this present work, the peel-off tape test was extended up to 10 times to evaluate the adherence of the coating [15]. The appearance of water droplets and FE-SEM images of ZnO-nt/PDMS-coated glass substrate before and after the peel-off tests are shown in Figure 6. The FESEM images showed that there are no major changes in the surface morphology before and after the peeloff tape test. Figure 7 shows the WCA of $\mathrm{ZnO}$-nt/PDMScoated glass substrate during 10 peel-off tape tests. There is no significant drop in the WCA after $10\left(160^{\circ}\right)$ peel-off tape tests, indicating the excellent adherence of the superhydrophobic coating. Nevertheless, we noticed that some nanoparticles were transferred onto the tape surface, suggesting the loss of unbound particles from the glass surface.

Based on the crystal structure and functional group, the excellent adherence of the superhydrophobic coating is explained schematically in Figure 8. An oxygen in the solvated zinc acetate forms a hydrogen bond with the $\mathrm{OH}$ group of glass (the area labelled as " $\mathrm{A}$ " in reaction (1)), while the oxygen of PDMS forms a hydrogen bond with $-\mathrm{H}$ of the solvated zinc group (the area marked as " $\mathrm{B}$ " in reaction (1)). Solvated zinc acetate acts as a "bridge" between the glass substrate and PDMS. In the meantime, the $-\mathrm{O}$ group from tetrahedral $\mathrm{ZnO}$ forms a hydrogen bond with the $-\mathrm{H}$ group of PDMS (the area labelled as "C" in reaction (1)). After heat treatment at $80^{\circ} \mathrm{C}$ and UV exposure, this bridge provides a better adhesion due to the formation of Si-O-Zn linkages (the area marked as " $\mathrm{D}$ " in reaction (2)). This is further confirmed by the appearance of a band at $946 \mathrm{~cm}^{-1}$ in FTIR results. Upon heat treatment, zinc acetate is decomposed into interstice of the inorganic silica network. This is clearly affirmed by the FTIR results, which shows the presence of $\mathrm{Si}-\mathrm{O}-\mathrm{Zn}$ and $\mathrm{Si}-\mathrm{O}-\mathrm{Si}$ bands, corresponding to a strong bonding interaction between the glass substrate, $\mathrm{ZnO}$, and silylating agent.

\section{Conclusion}

Superhydrophobic glass substrates with excellent adhesion have been successfully developed using PDMS and $\mathrm{ZnO}$-nt via a facile spray coating and UV-curing techniques. The surface free energy, surface roughness, and morphology are the influencing factors to achieve the maximum superhydrophobicity. The ZnO-nt/PDMS-coated glass substrate exhibited a high surface roughness $\left(791 \mathrm{~nm}\right.$ with WCA of $\left.165 \pm 1^{\circ}\right)$ when compared to $\mathrm{ZnO}-\mathrm{C} / \mathrm{PDMS}$ ( $658 \mathrm{~nm}$ with WCA of $153 \pm 2^{\circ}$ ). The superhydrophobic coating is chemically stable in acid and neutral $\mathrm{pH}$ environment. This kind of superhydrophobic coating would have promising applications in self-cleaning cloths, glass, windows of high-rise buildings, optical devices, solar panels, and electronic devices.

\section{Data Availability}

The raw/processed data used to support the findings of this study have not been made available because the data is a part of an ongoing study.

\section{Conflicts of Interest}

The authors declare that there are no conflicts of interest regarding the publication of this paper.

\section{Acknowledgments}

The authors are thankful to the Universiti Sains Malaysia (USM) for providing the necessary facilities and funding this research work under Research University (RU) grant no. 814281. The authors are also grateful to the Ministry of Higher Education (MOHE) Malaysia for funding under Fundamental Research Grant Scheme (FRGS) grant no. 6071319.

\section{Supplementary Materials}

The figure describes about the preparation method and chemical bonding responsible for sample adherence. The first picture shows the facile spray method on glass substrate with $\mathrm{ZnO}$-nt/PDMS mixture. The second picture describes about bonding that occurred between glass substrate and mixture. The final picture shows the water droplet on the coated glass substrate coated with ZnO-nt/ PDMS mixture. (Supplementary Materials)

\section{References}

[1] J. Li, S. Lu, W. Xu et al., "Fabrication of stable $\mathrm{Ni}-\mathrm{Al}_{4} \mathrm{Ni}_{3}-$ $\mathrm{Al}_{2} \mathrm{O}_{3}$ superhydrophobic surface on aluminum substrate for self-cleaning, anti-corrosive and catalytic performance," Journal of Materials Science, vol. 53, no. 2, pp. 1097-1109, 2018.

[2] N. Wang, D. Xiong, Y. Deng, Y. Shi, and K. Wang, "Mechanically robust superhydrophobic steel surface with anti-icing, UV-durability, and corrosion resistance properties," ACS Applied Materials \& Interfaces, vol. 7, no. 11, pp. 6260-6272, 2015.

[3] Y. Shi, W. Yang, X. Feng, Y. Wang, and G. Yue, "Fabrication of superhydrophobic $\mathrm{ZnO}$ nanorods surface with corrosion resistance via combining thermal oxidation and surface modification," Materials Letters, vol. 151, pp. 24-27, 2015.

[4] S. Gao, J. Huang, S. Li et al., "Facile construction of robust fluorine-free superhydrophobic $\mathrm{TiO}_{2} @$ fabrics with excellent anti-fouling, water-oil separation and UV-protective properties," Materials \& Design, vol. 128, pp. 1-8, 2017.

[5] C.-H. Xue, J. Chen, W. Yin, S.-T. Jia, and J.-Z. Ma, "Superhydrophobic conductive textiles with antibacterial property by coating fibers with silver nanoparticles," Applied Surface Science, vol. 258, no. 7, pp. 2468-2472, 2012. 
[6] D. Zhang, L. Wang, H. Qian, and X. Li, "Superhydrophobic surfaces for corrosion protection: a review of recent progresses and future directions," Journal of Coatings Technology and Research, vol. 13, no. 1, pp. 11-29, 2016.

[7] H. Lei, J. Xiao, L. Zheng et al., "Superhydrophobic coatings based on colloid silica and fluorocopolymer," Polymer, vol. 86, pp. 22-31, 2016.

[8] I. Das, M. K. Mishra, S. K. Medda, and G. De, "Durable superhydrophobic $\mathrm{ZnO}-\mathrm{SiO}_{2}$ films: a new approach to enhance the abrasion resistant property of trimethylsilyl functionalized $\mathrm{SiO}_{2}$ nanoparticles on glass," RSC Advances, vol. 4, no. 98, pp. 54989-54997, 2014.

[9] X. Chen, Y. Chen, T. Jin et al., "Fabrication of superhydrophobic coating from non-fluorine siloxanes via a one-pot sol-gel method," Journal of Materials Science, vol. 53, no. 16, pp. 11253-11264, 2018.

[10] X. Wu, Q. Fu, D. Kumar et al., "Mechanically robust superhydrophobic and superoleophobic coatings derived by sol-gel method," Materials \& Design, vol. 89, pp. 1302-1309, 2016.

[11] S. J. Hardman, N. Muhamad-Sarih, H. J. Riggs et al., "Electrospinning superhydrophobic fibers using surface segregating end-functionalized polymer additives," Macromolecules, vol. 44, no. 16, pp. 6461-6470, 2011.

[12] N. Zhao, F. Shi, Z. Wang, and X. Zhang, "Combining layer-bylayer assembly with electrodeposition of silver aggregates for fabricating superhydrophobic surfaces," Langmuir, vol. 21, no. 10, pp. 4713-4716, 2005.

[13] J. Liu, X. Xiao, Y. Shi, and C. Wan, "Fabrication of a superhydrophobic surface from porous polymer using phase separation," Applied Surface Science, vol. 297, Supplement C, pp. 33-39, 2014.

[14] S. Li, S. Zhang, and X. Wang, "Fabrication of superhydrophobic cellulose-based materials through a solution-immersion process," Langmuir, vol. 24, no. 10, pp. 5585-5590, 2008.

[15] A. Cholewinski, J. Trinidad, B. McDonald, and B. Zhao, "Bioinspired polydimethylsiloxane-functionalized silica particles epoxy bilayer as a robust superhydrophobic surface coating," Surface and Coatings Technology, vol. 254, pp. 230-237, 2014.

[16] K. Li, X. Zeng, H. Li, X. Lai, and H. Xie, "Effects of calcination temperature on the microstructure and wetting behavior of superhydrophobic polydimethylsiloxane/silica coating," Colloids and Surfaces A: Physicochemical and Engineering Aspects, vol. 445, pp. 111-118, 2014.

[17] F. Yang and Z. Guo, "Bio-inspired design of a transparent $\mathrm{TiO}_{2} / \mathrm{SiO}_{2}$ composite gel coating with adjustable wettability," Journal of Materials Science, vol. 51, no. 16, pp. 7545-7553, 2016.

[18] T. Rezayi and M. H. Entezari, "Achieving to a superhydrophobic glass with high transparency by a simple sol-gel-dipcoating method," Surface and Coatings Technology, vol. 276, pp. 557-564, 2015.

[19] R. P. S. Chakradhar and V. Dinesh Kumar, "Water-repellent coatings prepared by modification of $\mathrm{ZnO}$ nanoparticles," Spectrochimica Acta. Part A, Molecular and Biomolecular Spectroscopy, vol. 94, pp. 352-356, 2012.

[20] R. V. Lakshmi and B. J. Basu, "Fabrication of superhydrophobic sol-gel composite films using hydrophobically modified colloidal zinc hydroxide," Journal of Colloid and Interface Science, vol. 339, no. 2, pp. 454-460, 2009.

[21] K. A. Saharudin, S. Sreekantan, N. Basiron et al., "Improved super-hydrophobicity of eco-friendly coating from palm oil fuel ash (POFA) waste," Surface and Coatings Technology, vol. 337, pp. 126-135, 2018.

[22] X. Hao, G. Wu, L. Wang et al., "Superhydrophobic surfaces based on ZnO-constructed hierarchical architectures," Microelectronic Engineering, vol. 141, pp. 44-50, 2015.

[23] S. Ammar, K. Ramesh, B. Vengadaesvaran, S. Ramesh, and A. K. Arof, "Amelioration of anticorrosion and hydrophobic properties of epoxy/PDMS composite coatings containing nano ZnO particles," Progress in Organic Coatings, vol. 92, pp. 54-65, 2016.

[24] L. Xu, G. Zheng, J. Wang et al., "Leaf-like ZnO nanostructure and its excellent photocatalytic activity," Materials Letters, vol. 122, pp. 1-4, 2014.

[25] D. Jesuvathy Sornalatha and P. Murugakoothan, "Characterization of hexagonal $\mathrm{ZnO}$ nanostructures prepared by hexamethylenetetramine (HMTA) assisted wet chemical method," Materials Letters, vol. 124, Supplement C, pp. 219-222, 2014.

[26] A. M. El-Rafei and M. Zawrah, "Effect of alkali concentration and reaction time on the morphology of $\mathrm{ZnO}$ nanomicroparticles prepared by hydrothermal method," Journal of Ceramic Science and Technology, vol. 5, no. 3, pp. 193198, 2014.

[27] J. Lin, D. Wang, D. Chen et al., "Preparation and enhanced photocatalytic performance of one-dimensional $\mathrm{ZnO}$ nanorods," Environmental Progress \& Sustainable Energy, vol. 34, no. 1, pp. 74-80, 2015.

[28] J. Chang, M. Ahmad, W. Wlodarski, and E. Waclawik, "Selfassembled $3 \mathrm{D} \mathrm{ZnO}$ porous structures with exposed reactive $\{0001\}$ facets and their enhanced gas sensitivity," Sensors, vol. 13, no. 7, pp. 8445-8460, 2013.

[29] C. Wang, J. Lu, L. Zhou et al., "Effects of long-term exposure to zinc oxide nanoparticles on development, zinc metabolism and biodistribution of minerals ( $\mathrm{Zn}, \mathrm{Fe}, \mathrm{Cu}, \mathrm{Mn})$ in mice," PLoS One, vol. 11, no. 10, article e0164434, 2016.

[30] M. Gupta, V. K. Mahajan, K. S. Mehta, and P. S. Chauhan, "Zinc therapy in dermatology: a review," Dermatology Research and Practice, vol. 2014, Article ID 709152, 11 pages, 2014.

[31] R. P. S. Chakradhar, V. D. Kumar, J. L. Rao, and B. J. Basu, "Fabrication of superhydrophobic surfaces based on $\mathrm{ZnO}-$ PDMS nanocomposite coatings and study of its wetting behaviour," Applied Surface Science, vol. 257, no. 20, pp. 8569-8575, 2011.

[32] B. Zhou, Y. Gao, Y. Mao, and W. Wen, "Facile preparation of superhydrophobic PDMS with patternable and controllable water adhesion characteristics," Journal of Materials Science, vol. 52, no. 19, pp. 11428-11441, 2017.

[33] N. K. Neelakantan, P. B. Weisensee, J. W. Overcash, E. J. Torrealba, W. P. King, and K. S. Suslick, "Spray-on omniphobic ZnO coatings,” RSC Advances, vol. 5, no. 85, pp. 6924369250, 2015.

[34] J. Li, H. Wan, X. Liu, Y. Ye, H. Zhou, and J. Chen, "Facile fabrication of superhydrophobic $\mathrm{ZnO}$ nanoparticle surfaces with erasable and rewritable wettability," Applied Surface Science, vol. 258, no. 22, pp. 8585-8589, 2012.

[35] T. Simovich, A. H. Wu, and R. N. Lamb, "Hierarchically rough, mechanically durable and superhydrophobic epoxy coatings through rapid evaporation spray method," Thin Solid Films, vol. 589, pp. 472-478, 2015.

[36] K. Vignesh, S. Kang, B. S. Kwak, and M. Kang, "Meso-porous $\mathrm{ZnO}$ nano-triangles @ graphitic- $\mathrm{C}_{3} \mathrm{~N}_{4}$ nano-foils: fabrication 
and recyclable photocatalytic activity," Separation and Purification Technology, vol. 147, pp. 257-265, 2015.

[37] J. Zimmermann, F. A. Reifler, G. Fortunato, L.-C. Gerhardt, and S. Seeger, "A simple, one-step approach to durable and robust superhydrophobic textiles," Advanced Functional Materials, vol. 18, no. 22, pp. 3662-3669, 2008.

[38] G. Momen and M. Farzaneh, "A ZnO-based nanocomposite coating with ultra water repellent properties," Applied Surface Science, vol. 258, no. 15, pp. 5723-5728, 2012.

[39] T. Jiang and Z. Guo, "Robust superhydrophobic tungsten oxide coatings with photochromism and UV durability properties," Applied Surface Science, vol. 387, pp. 412-418, 2016.

[40] J. Wang, G. Wu, J. Shen et al., "Scratch-resistant improvement of sol-gel derived nano-porous silica films," Journal of Sol-Gel Science and Technology, vol. 18, no. 3, pp. 219-224, 2000.

[41] P. H. C. Camargo, T. S. Rodrigues, A. G. M. da Silva, and J. Wang, "Controlled aynthesis: nucleation and growth in solution," in Metallic Nanostructures, pp. 49-74, Springer, 2015.

[42] G. Amin, M. H. Asif, A. Zainelabdin, S. Zaman, O. Nur, and M. Willander, "Influence of $\mathrm{pH}$, precursor concentration, growth time, and temperature on the morphology of $\mathrm{ZnO}$ nanostructures grown by the hydrothermal method," Journal of Nanomaterials, vol. 2011, Article ID 269692, 9 pages, 2011.

[43] R. A. Mereu, A. Mesaros, T. Petrisor Jr et al., "Synthesis, characterization and thermal decomposition study of zinc propionate as a precursor for $\mathrm{ZnO}$ nano-powders and thin films," Journal of Analytical and Applied Pyrolysis, vol. 104, Supplement C, pp. 653-659, 2013.

[44] K. Jeevajothi, R. Subasri, and K. R. C. Soma Raju, "Transparent, non-fluorinated, hydrophobic silica coatings with improved mechanical properties," Ceramics International, vol. 39, no. 2, pp. 2111-2116, 2013.

[45] B. Arkles, "Hydrophobicity, hydrophilicity and silanes: water, water everywhere is the refrain from the rhyme of the ancient mariner and a concern of every modern coatings technologist," Paint and Coatings Industry, 2006.

[46] L. Ejenstam, A. Swerin, and P. M. Claesson, "Toward superhydrophobic polydimethylsiloxane-silica particle coatings," Journal of Dispersion Science and Technology, vol. 37, no. 9, pp. 1375-1383, 2016.

[47] M. Tenjimbayashi and S. Shiratori, "Highly durable superhydrophobic coatings with gradient density by movable spray method," Journal of Applied Physics, vol. 116, no. 11, article 114310,, 2014.

[48] N. Bai, Q. Li, H. Dong, C. Tan, P. Cai, and L. Xu, “A versatile approach for preparing self-recovering superhydrophobic coatings," Chemical Engineering Journal, vol. 293, pp. 75-81, 2016. 


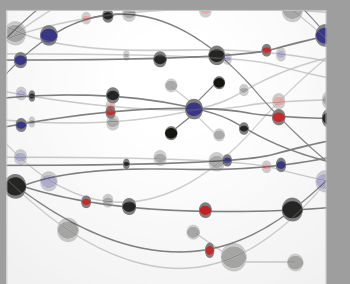

The Scientific World Journal
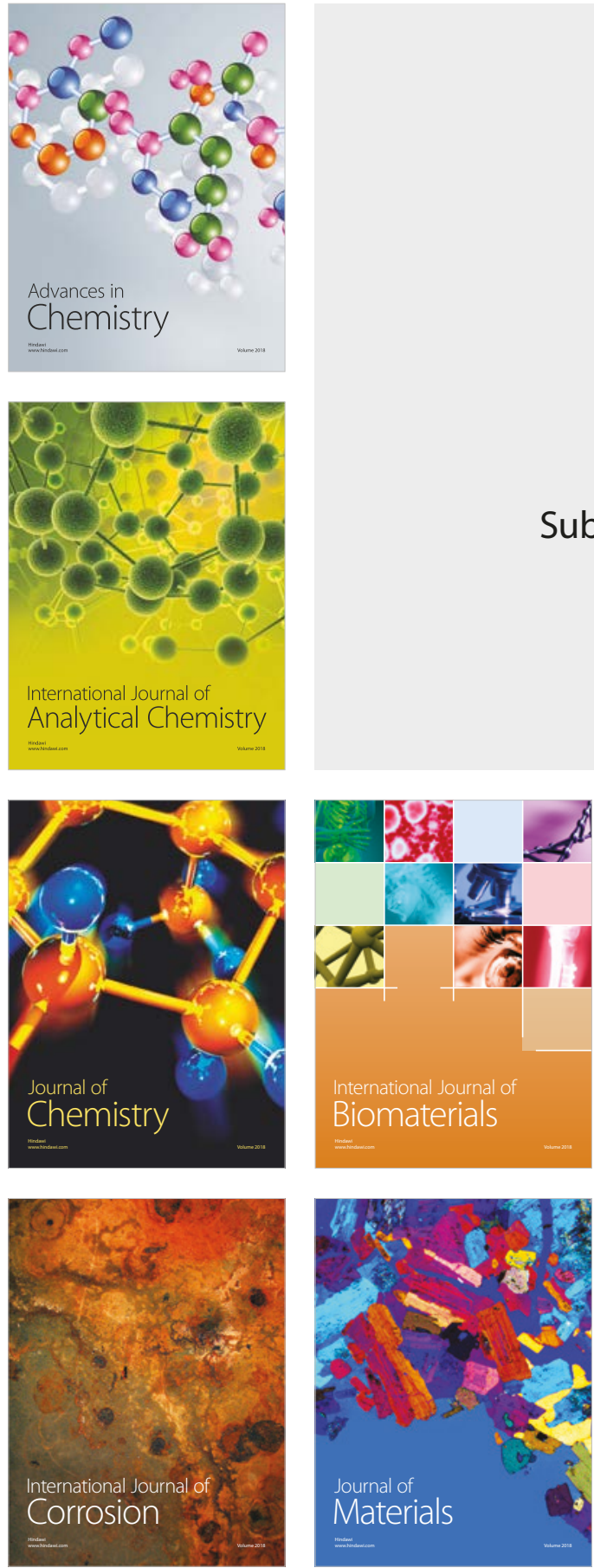

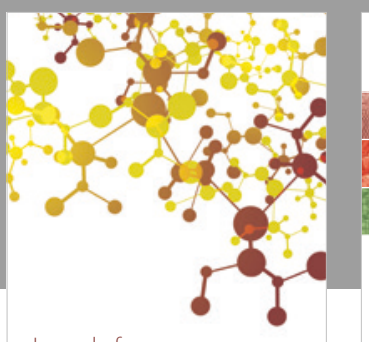

Journal of

Applied Chemistry
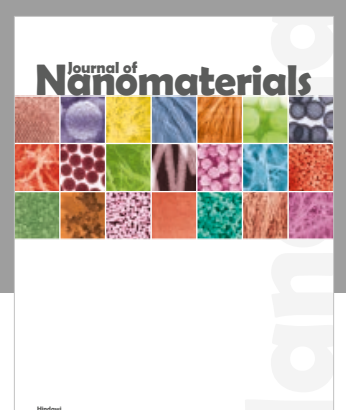

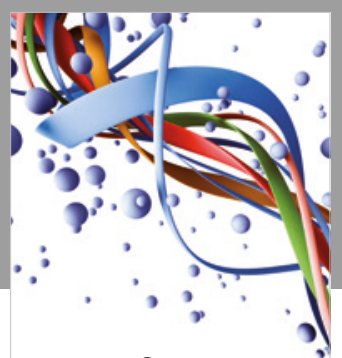

Scientifica

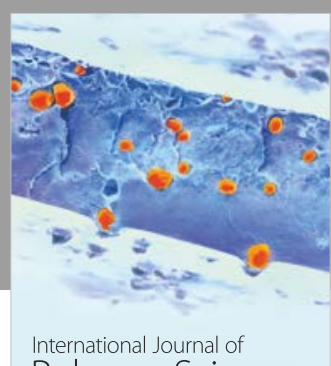

Polymer Science

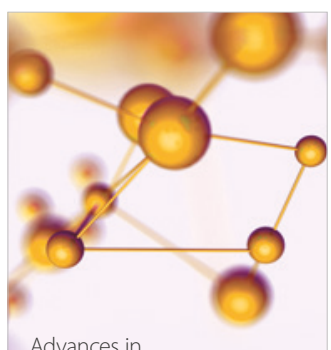

Physical Chemistry
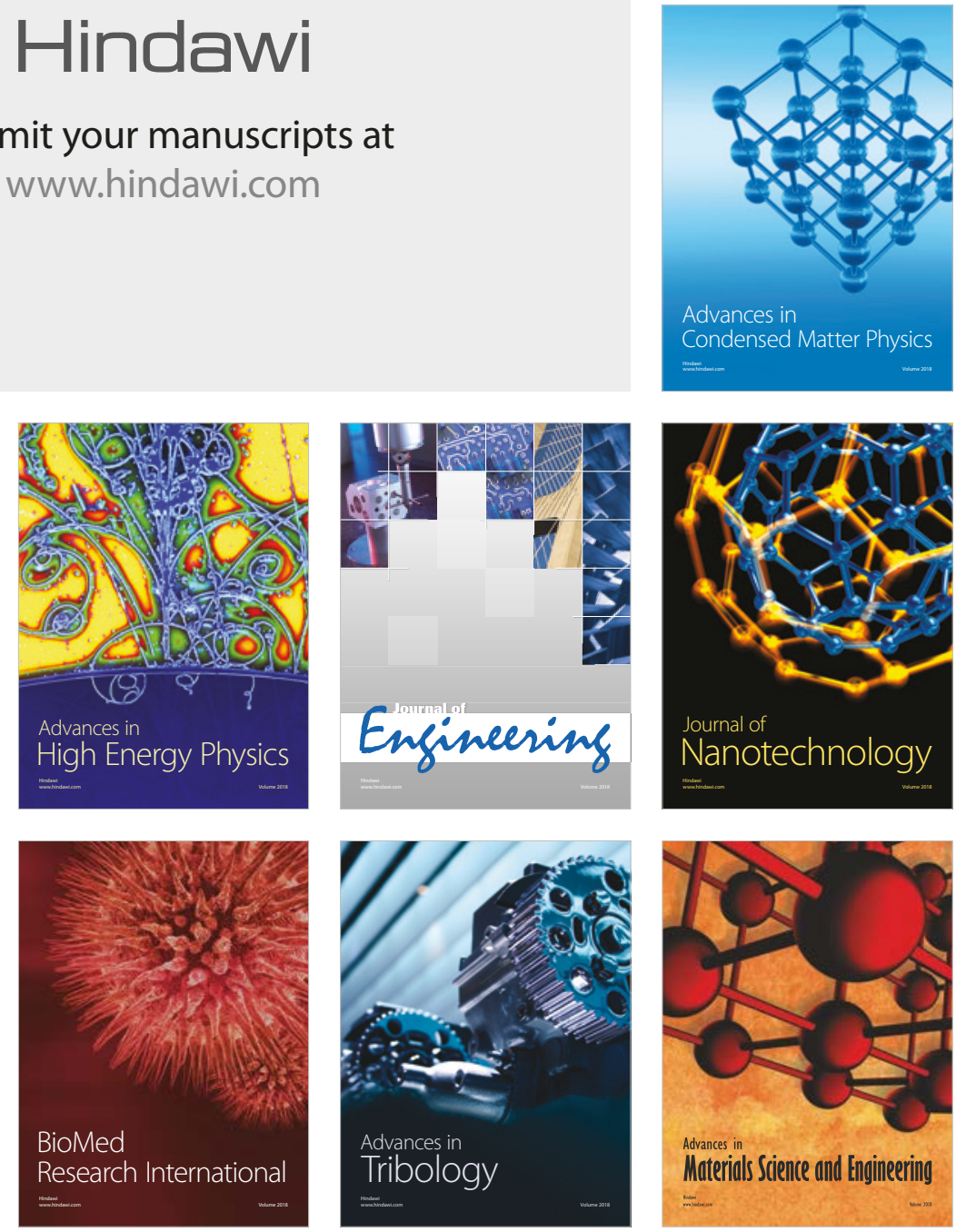